\title{
Robotic treatment of giant adrenal myelolipoma: A case report and review of the literature
}

\author{
GIOVANNI COCHETTI, ALESSIO PALADINI, ANDREA BONI, ELISA SILVI, ALBERTO TIEZZI, \\ JACOPO ADOLFO ROSSI DE VERMANDOIS and ETTORE MEARINI
}

\begin{abstract}
Department of Surgical and Biomedical Sciences, Inter-Divisional Urology Clinic (Perugia-Terni), Santa Maria della Misericordia University Hospital, I-06156 Perugia, Italy
\end{abstract}

Received August 9, 2018; Accepted February 13, 2019

DOI: $10.3892 / \mathrm{mco} .2019 .1823$

\begin{abstract}
Adrenal myelolipoma is a rare mesenchymal tumour with benign biological behaviour that is mainly composed of mature adipose and myeloid tissue. Both sexes are equally affected, most commonly between the fifth and seventh decades of life. The diagnosis of adrenal myelolipoma is mostly incidental. Although it may occasionally be associated with necrosis, rupture and haemorrhage, causing abdominal pain, this tumour is usually asymptomatic. Consequently, management is conservative, while surgical treatment is reserved for symptomatic cases, or for masses growing quickly or to a size $>6 \mathrm{~cm}$. Giant myelolipomas (sized $>10 \mathrm{~cm}$ ) are rare. Open radical adrenalectomy is the standard treatment for giant myelolipomas, while the minimally invasive approach has been used in only few cases. We herein report the case of a patient with a giant adrenal myelolipoma who underwent robotic partial adrenalectomy. To the best of our knowledge, this is the largest giant adrenal myelolipoma treated with robotic surgery reported in the literature to date. A 55-year-old male patient underwent an abdominal computed tomography scan during follow-up after radical prostatectomy for prostate cancer Gleason Score 6 (ISUP 1) due to biochemical recurrence. The examination revealed a right hypodense adrenal mass, sized 16x13 cm. Abdominal magnetic resonance imaging confirmed the presence of characteristics suggestive of a myelolipoma. The patient did not report any symptoms. Due to the benign characteristics of the mass, robotic partial
\end{abstract}

Correspondence to: Dr Andrea Boni, Department of Surgical and Biomedical Sciences, Inter-Divisional Urology Clinic (Perugia-Terni), Santa Maria della Misericordia University Hospital, 1 Piazzale Menghini, I-06156 Perugia, Italy

E-mail: andrea-boni@hotmail.it

Abbreviations: CT, computed tomography; MRI, magnetic resonance imaging; OT, operative time; EBL, estimated blood loss

Key words: giant myelolipoma, robotic adrenalectomy, partial adrenalectomy, adrenal myelolipoma, adrenal masses, mesenchymal tumour, benign adrenal tumour, robotic surgery, robotic transperitoneal adrenalectomy adrenalectomy and enucleation of the mass were performed. The operative time and estimated blood loss were $205 \mathrm{~min}$ and $100 \mathrm{ml}$, respectively. No intra- or postoperative complications occurred. The patient was mobilized on the first postoperative day and the time to flatus was $36 \mathrm{~h}$; the length of hospitalization was 4 days. Histological examination confirmed the diagnosis of adrenal myelolipoma, sized 18x11.5x6 cm. No tumour recurrence occurred over a follow-up period of 12 months. In conclusion, robotic surgery allows performing partial adrenalectomy with a lower risk of bleeding and with preservation of healthy adrenal tissue, which is of paramount importance for the patient as it reduces recovery time and the need for medical substitution therapy.

\section{Introduction}

Adrenal myelolipoma is a rare mesenchymal tumour with benign biological behaviour that is mainly composed of mature adipose and myeloid tissue (1). Its pathogenesis is largely unknown, but infection, inflammation, necrosis, stressful lifestyle and an unbalanced diet are known risk factors; adrenal myelolipoma is also often associated with obesity, high levels of blood lipids, hypertension, diabetes and Cushing's disease (2). The two sexes are equally affected, mainly between the fifth and seventh decades of life (3). The most common site is the right adrenal gland (4), but other sites, such as the presacral area, spleen, stomach, lung, liver, retroperitoneum and testis, are also reported (5).

Adrenal myelolipoma is generally non-secretory and its diagnosis is most commonly incidental: It currently represents $10-15 \%$ of incidental adrenal masses discovered on imaging investigations, such as ultrasonography, computed tomography (CT) and magnetic resonance imaging (MRI). Myelolipoma is usually asymptomatic, but it may occasionally be associated with necrosis, rupture and haemorrhage, causing abdominal pain (6). Due to the absence of symptoms and its small size (usually $<4 \mathrm{~cm}$ ), the management of myelolipoma is usually conservative. Surgical treatment is recommended when the mass is symptomatic, or grows quickly or to a size of $>6 \mathrm{~cm} \mathrm{(6).} \mathrm{Adrenalectomy} \mathrm{must} \mathrm{be} \mathrm{performed} \mathrm{in} \mathrm{case} \mathrm{of}$ malignant or potentially malignant tumors (1). Myelolipoma is defined as 'giant' when its greatest diameter is $>10 \mathrm{~cm}$ (2), which is a rare clinical occurrence. Open radical surgery is 
the standard treatment of choice for giant myelolipomas, while the minimally invasive approach has been used in only a few cases (7). We herein present the case of a patient with an $18-\mathrm{cm}$ adrenal myelolipoma who was treated by robotic partial adrenalectomy. To the best of our knowledge, this is the largest adrenal myelolipoma treated with robotic surgery reported in the literature to date.

\section{Case report}

A 55-year-old male patient underwent an abdominal CT scan during follow-up after radical prostatectomy. The examination revealed a right adrenal mass, sized 16x13 cm, homogeneous, hypodense (<-30 HU), imprinting on the right liver lobe and dislocating the right kidney downwards, the vena cava, duodenum and pancreas medially, and the ascending colon and gallbladder anteriorly. Following administration of contrast medium, the adrenal lesion exhibited poor enhancement with a rapid washout. The abdominal MRI confirmed the presence of a right adrenal lesion, sized 16x13 cm. Hyperintense on T1-weighted, isointense on T2-weighted and hypointense on fat-suppression images, without significant contrast enhancement, characteristics suggestive of a myelolipoma (Fig. 1). The patient did not report any symptoms, but exhibited a deformation of the right abdominal contour. Staging workup excluded other adrenal diseases.

The patient did not have other major comorbidities, and had a Charlson Comorbidity index score of 3 and an Eastern Cooperative Oncology Group performance status score of 0 .

Due to the benign characteristics of the mass, it was decided to perform transperitoneal robotic partial adrenalectomy in order to preserve adrenal healthy tissue and maintain functional adrenal integrity in a young patient undergoing surgery for a benign lesion.

Written informed consent was obtained from the patient prior to surgery.

The operation was performed by a robotic-skilled urologist, using the DaVinci ${ }^{\circledR}$ Model Xi Surgical System (Intuitive Surgical, Inc., Sunnyvale, CA, USA) in the Tertiary Care Hospital Santa Maria di Terni (Terni, Italy). The patient was placed in a left flank position with a $45^{\circ}$ side tilt. The optical trocar was inserted on the intersection between the transumbilical and periumbilical lines. Two more robotic trocars and two trocars for the assistant were inserted (Fig. 2). The triangular hepatic ligament was dissected to mobilize the liver, followed by enucleation of the mass (Fig. 3). The operative time (OT) and estimated blood loss (EBL) were $205 \mathrm{~min}$ and $100 \mathrm{ml}$, respectively. No intra- or postoperative complications occurred. On the first postoperative day, the nasogastric tube was removed and the patient was mobilized; the time to flatus was $36 \mathrm{~h}$, oral feeding was initiated 3 days after surgery and the length of hospitalization was 4 days. The histological examination confirmed the diagnosis of adrenal myelolipoma, sized 18x11.5x6 cm. Follow-up examinations included an abdominal ultrasound and CT scan at 6 and 12 months after surgery, respectively. At 12 months of follow-up no recurrence had occurred.

A systematic bibliography search up to January 2018 was conducted through PubMed, Web of Science and Scopus. One of the authors (AP) independently performed online bibliographic research in order to identify titles and abstracts of interest. All titles and abstracts were assessed to select those focusing on minimally invasive adrenalectomy for sizeable masses. Subsequently, the full text of the selected articles was independently screened by two authors (ES and JARV) for eligibility (Table I).

\section{Discussion}

Adrenal myelolipoma is a rare benign tumour with a prevalence of $0.08-0.2 \%$ (3) that consists of mature adipose and hematopoietic tissue (8). Myelolipoma was first described by Gierke in 1905, and was named 'formations myelolipomatoses' by Oberling in 1929 (9). In the majority of the cases, it is incidentally diagnosed during clinical workup for other reasons. Myelolipoma mainly presents with abdominal discomfort and pain due to necrosis, rupture, haemorrhage, or even haemorrhagic shock (6). The mean size at the time of diagnosis is $\sim 4 \mathrm{~cm}$, while myelolipomas $>10 \mathrm{~cm}$ in greatest diameter are defined as 'giant' (2). The management of smaller, asymptomatic, slow-growing lesions is conservative, and patients are monitored by abdominal CT or MRI annually or biannually (2). Surgical treatment is recommended for asymptomatic tumours $>6 \mathrm{~cm}$ in diameter, for symptomatic lesions and for those exhibiting fast growth (6). In the AACE/AAES Adrenal Incidentaloma Guidelines, resection of myelolipoma may be considered under certain conditions, such as the presence of clinical symptoms or a diameter of $>4 \mathrm{~cm}$ (10). Based on the preoperative imaging examinations, partial adrenalectomy was considered to be the best choice in the present case.

An open or a minimally invasive approach is selected according to the size of the lesion and the skills of the surgeon. The open approach includes lumbar, subcostal, posterior or transabdominal laparotomy, and is usually reserved for giant masses or as an emergency intervention in cases with rupture and haemorrhage.

The advantages of the laparoscopic compared with the traditional approach are less pain, faster recovery and shorter hospitalization, and it is usually reserved for smaller myelolipomas $(11,12)$. Robotic surgery is being increasingly used in different common surgical procedures, although its applicability in adrenal surgery remains debated upon $(13,14)$. A magnified $3 \mathrm{D}$ view of the operative field, the absence of tremor, wristed instruments and improved ergonomics are considered invaluable advantages over the laparoscopic approach.

Giant myelolipomas are associated with more intraoperative complications, such as bleeding, capsular breach and a higher risk of local recurrence $(9,15)$. Morelli et al reported better results with the robotic vs. the laparoscopic approach in patients with large adrenal tumours ( $>6 \mathrm{~cm}$ in diameter). The OT for lesions sized $>6 \mathrm{~cm}$ was shorter in the robotic group (171.3 vs. $260.0 \mathrm{~min}, \mathrm{P}=0.002)$. There were no significant differences between the two groups regarding the rate of conversion, intra- and postoperative complications $(\mathrm{P}=0.49$, 0.95 and 0.96 , respectively) (16).

However, only few cases of minimally invasive adrenalectomy for giant adrenal myelolipomas have been reported to date (Table I). Campos Arbulú et al described a laparoscopic adrenalectomy for a 14-cm myelolipoma; no complications occurred and the length of hospitalization was $48 \mathrm{~h}$ (17). 

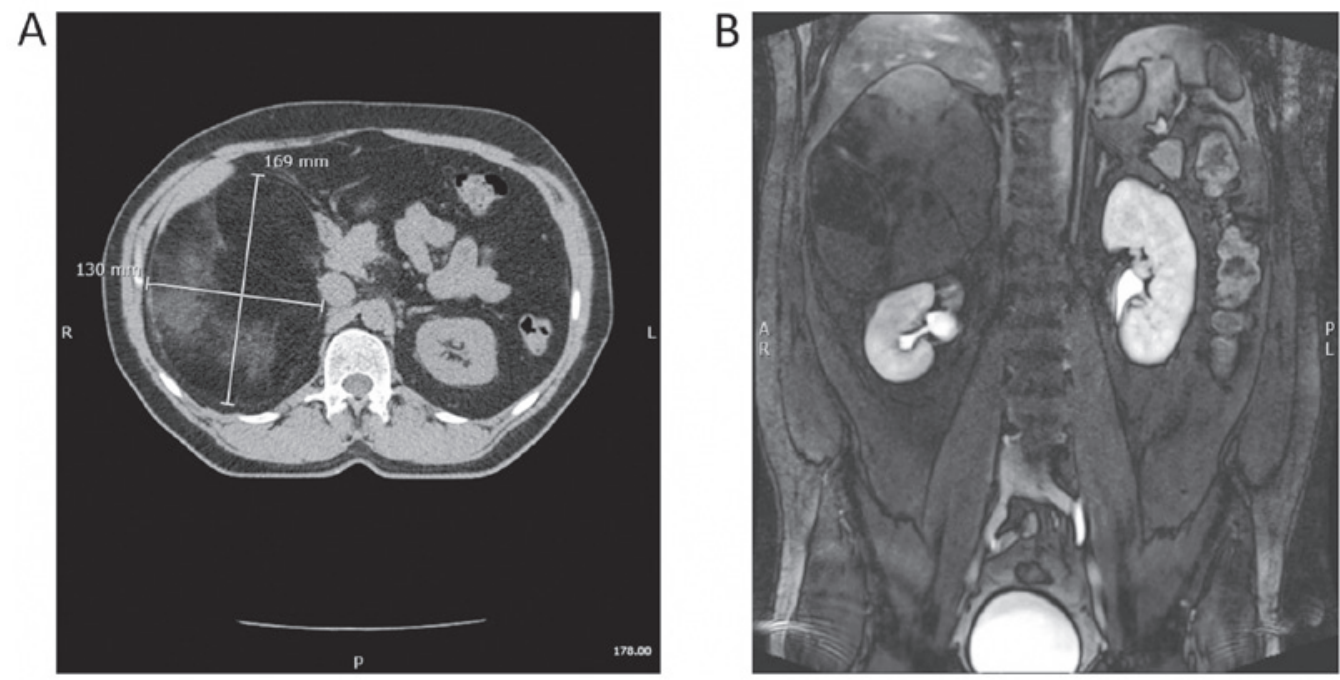

Figure 1. (A) Computed tomography and (B) magnetic resonance imaging scan showing the giant right adrenal myelolipoma.

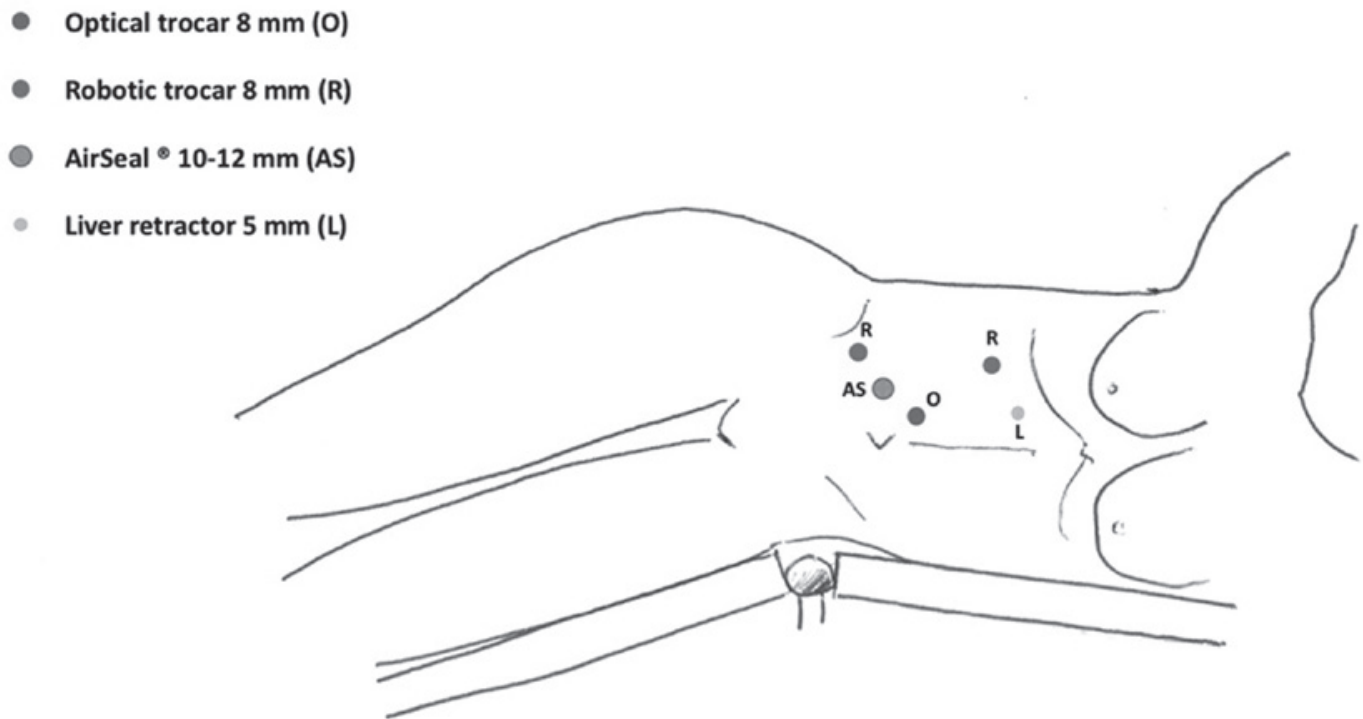

Figure 2. Trocar placement. The optical trocar $(\mathrm{O})$ was positioned between the transumbilical and periumbilical lines. Two robotic trocars $(\mathrm{R})$ were placed on the pararectal line at $8 \mathrm{~cm}$ from O. The AirSeal ${ }^{\circledR}$ trocar (AS) was placed between $\mathrm{O}$ and the more caudal R. The liver retractor trocar (L) was placed subxifoidally on the paraumbilical line.

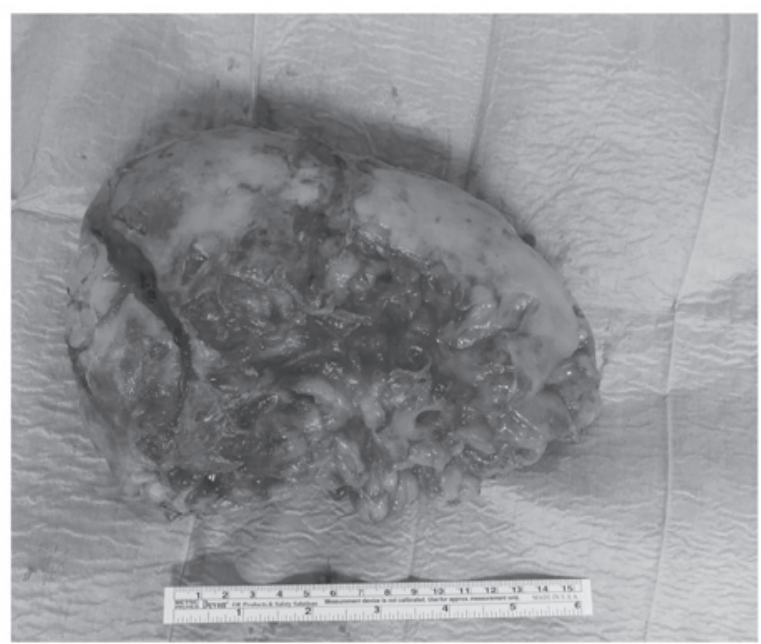

Figure 3. Macroscopic view of the resected giant myelolipoma.
Undre et al performed robotic adrenalectomy for a $13.9-\mathrm{cm}$ adrenal myelolipoma. The OT was $155 \mathrm{~min}$ and the EBL was $300 \mathrm{ml}$. No complications occurred and the length of hospitalization was 4 days (18). Brunaud et al performed 100 robotic adrenalectomies; tumour capsule rupture occurred in only 1 patient (1\%) with a $7.5-\mathrm{cm}$ lesion (19). There was 1 case of conversion to laparoscopy due to camera malfunction, in 4 cases open conversion was necessary due to bleeding and difficulty to identify the adrenal vein in 1 patient with a $7-\mathrm{cm}$ mass. Of note, all open conversions occurred in patients with high BMI ( $\left.\geq 29 \mathrm{~kg} / \mathrm{m}^{2}, 75 \%\right)$ and large tumours ( $\left.\geq 6 \mathrm{~cm}, 50 \%\right)(15)$. Agcaoglu et al performed 24 robotic and 38 laparoscopic adrenalectomies. Tumour size was similar in both groups $(6.5 \pm 0.4$, range $5-10.2 \mathrm{~cm}$ for the robotic group; $6.2 \pm 0.3$, range $5-15 \mathrm{~cm}$ for the laparoscopic group) as were age and sex. The robotic group had lower BMI $\left(27.1 \pm 0.8\right.$ vs. $\left.30.2 \pm 0.9 \mathrm{~kg} / \mathrm{m}^{2}\right)$. The robotic approach was associated with a shorter OT (159 vs. $187 \mathrm{~min}$; 
Table I. Cases of mini-invasive surgery for adrenal masses.

\begin{tabular}{|c|c|c|c|c|c|}
\hline Study ID & Year & Technique & No. of patients & Tumour size $(\mathrm{cm})$ & Refs. \\
\hline Molnar, et al & 2017 & $\mathrm{R}$ & 1 & $4.6 \times 4.1$ & $(5)$ \\
\hline Economopoulos, et al & 2017 & $\mathrm{~L} / \mathrm{R}$ & $415 / 353$ & 2.8-6.2/2.57-6.5 (mean) & $(21)$ \\
\hline Campos Arbulù, et al & 2017 & $\mathrm{~L}$ & 1 & 14 & $(17)$ \\
\hline Burttet, et al & 2017 & $\mathrm{R}$ & 1 & 8.3 & $(22)$ \\
\hline Morelli, et al & 2016 & $\mathrm{~L} / \mathrm{R}$ & $41 / 41$ & $4.7 / 4.9$ (mean) & $(16)$ \\
\hline Teo and Lim & 2016 & $\mathrm{~L} / \mathrm{R}$ & $263 / 569$ & $1-15 / 1-13.9$ & (7) \\
\hline Deniwar, et al & 2015 & $\mathrm{R}$ & 1 & 3.9 & $(23)$ \\
\hline Akarsu, et al & 2014 & $\mathrm{R}$ & 8 & $2-9$ & $(24)$ \\
\hline Brandao, et al & 2013 & $\mathrm{~L} / \mathrm{R}$ & $323 / 277$ & $3.78 \pm 1.06-3.86 \pm 1.32$ & $(25)$ \\
\hline Yates, et al & 2010 & $\mathrm{R}$ & 1 & 1.5 & $(26)$ \\
\hline
\end{tabular}

$\mathrm{R}$, robotic; L, laparoscopic.

$\mathrm{P}=0.043$ ) and lower EBL (87 vs. $167 \mathrm{ml} ; \mathrm{P}=0.147$ ). The conversion rate was markedly higher in the laparoscopic group (11 vs. 4\%) and the causes of conversion in the laparoscopic group included bleeding from the renal vein or the adrenal gland, adhesion to the vena cava and difficulty with the dissection plane; in the robotic group, the main cause of conversion was the adherence of the tumour to the renal hilum (20). To the best of our knowledge, the case presented herein is the largest giant myelolipoma treated by robotic approach that has been reported in the literature to date.

A robotic partial adrenalectomy was performed, with enucleation of the mass. No intra- or postoperative complications occurred. The EBL was $100 \mathrm{ml}$, which was comparable with previous reported cases $(7,21,25)$. The choice of partial adrenalectomy for a benign tumour was based on finding an avascular plane between the tumour capsule and the healthy surrounding adrenal tissue, in order to significantly reduce intraoperative bleeding and preserve healthy adrenal tissue. The robotic approach allowed a safer preservation of the adrenal vessels due to the magnified $3 \mathrm{D}$ vision and the wristed instruments that permitted more accurate dissection. Furthermore, no capsular effraction was observed. Several studies demonstrated the feasibility and safety of robotic partial adrenalectomy, with satisfactory oncological as well as functional results (9). In the present case, the functional outcome was optimal, as the patient did not require steroid supplementation.

In conclusion, the standard treatment for giant myelolipoma is laparotomic adrenalectomy. However, while the minimally invasive techniques were initially used for smaller lesions, the improved laparoscopic and robotic instrumentations and the increasing experience of the surgeons have led to the wider application of the minimally invasive approach in more complex cases.

We consider the transperitoneal robotic approach to be a safe strategy for giant adrenal masses due to the better visualization of the operative field and more accurate dissection, decreasing the risk of capsular effraction. Moreover, the enucleation of the mass decreases the risk of bleeding, which is the most common cause of conversion, and enables preservation of adrenal functional healthy tissue.

\section{Acknowledgements}

Not applicable.

\section{Funding}

No funding was received.

\section{Availability of data and materials}

All the necessary information on the present case report is provided in this manuscript.

\section{Authors' contributions}

AP independently performed online bibliographic research in order to identify titles and abstracts of interest. GC and EM were responsible for the conception and design. AB, GC, ES, AT and JDV participated in either drafting or critically revising the article for important intellectual content. All authors have approved the final version of the manuscript to be published and agree to be accountable for all aspects of the work in ensuring that questions related to the accuracy or integrity of any part of the work are appropriately investigated and resolved.

\section{Ethics approval and consent to participate}

The study has been approved by an Internal Board Committee and written informed consent was obtained from the patient prior to surgery.

\section{Patient consent for publication}

The patient provided written consent regarding the publication of the case details and associated images.

\section{Competing interests}

The authors declare that they have no competing interests to disclose. 


\section{References}

1. Lam AK: Update on adrenal tumours in 2017 World Health Organization (WHO) of endocrine tumours. Endocr Pathol 28 : 213-227, 2017.

2. Bokhari MR and Bhimji S: Adrenal, myelolipoma. StatPearls NCBI Bookshelf, 2017.

3. Al-Bahri S, Tariq A, Lowentritt B and Nasrallah DV; Hindawi Publishing Corporation: Giant bilateral adrenal myelolipoma with congenital adrenal hyperplasia. Case Rep Surg 2014: 728198, 2014

4. Zhao J, Sun F, Jing X, Zhou W, Huang X, Wang H, Zhu Y, Yuan F and Shen $Z$ : The diagnosis and treatment of primary adrenal lipomatous tumours in Chinese patients: A 31-year follow-up study. Can Urol Assoc J 8: E132-E136, 2014.

5. Molnar C, Lata L, Pisica R, Russu C, Gherghinescu M, Molnar C, Borda A, Butiurca VO, Suciu BA and Copotoiu C: Anterior transabdominal laparoscopic adrenalectomy, without ligatures, for a symptomatic right adrenal myelolipoma with intratumorally haemorrhage. Chirurgia (Bucur) 112: 58-62, 2017.

6. Ramirez M and Misra S: Adrenal myelolipoma: To operate or not? A case report and review of the literature. Int J Surg Case Rep 5: 494-496, 2014.

7. Teo XL and Lim SK: Robotic assisted adrenalectomy: is it ready for prime time? Investig Clin Urol 57 (Suppl 2): S130-S146, 2016.

8. Federle M and Anne V: Adrenal myelolipoma. In: Diagnostic Imaging: Abdomen. 1st edition. Amirsys, Inc., Salt lake, ppIII2-24-25, 2004.

9. Oberling C: Les formations myelolipomateuses. Bull Assoc Fr Etud Cancer 18: 234-246, 1929.

10. Zeiger MA, Thompson GB, Duh QY, Hamrahian AH, Angelos P, Elaraj D, Fishman E and Kharlip J: MDAACE/AAES Adrenal Incidentaloma Guidelines. Endocr Pract 15 (Suppl 1), 2009.

11. Nomine-Criqui C, Germain A, Ayav A, Bresler L and Brunaud L: Robot-assisted adrenalectomy: Indications and drawbacks. Updates Surg 69: 127-133, 2017.

12. Cochetti G, Puxeddu E, Zingaro MD, D'Amico F, Cottini E, Barillaro F and Mearini E: Laparoscopic partial nephrectomy of thyroid cancer metastasis: Case report and review of the literature. OncoTargets Ther 6: 355-360, 2013.

13. Arezzo A, Bullano A, Cochetti G, Cirocchi R, Randolph J, Mearini E, Evangelista A, Ciccone G, Bonjer HJ and Morino M: Transperitoneal versus retroperitoneal laparoscopic adrenalectomy for adrenal tumours in adults. Cochrane Database Syst Rev: Dec 30, 2018 (Epub ahead of print).

14. Boni A, Cochetti G, Ascani S, Del Zingaro M, Quadrini F, Paladini A, Cocca D and Mearini E: Robotic treatment of oligometastatic kidney tumor with synchronous pancreatic metastasis: Case report and review of the literature. BMC Surg 18: 40, 2018.

15. Gumbs AA and Gagner M: Laparoscopic adrenalectomy. Best Pract Res Clin Endocrinol Metab 20: 483-499, 2006.
16. Morelli L, Tartaglia D, Bronzoni J, Palmeri M, Guadagni S, Di Franco G, Gennai A, Bianchini M, Bastiani L, Moglia A, et al: Robotic assisted versus pure laparoscopic surgery of the adrenal glands: A case-control study comparing surgical techniques. Langenbecks Arch Surg 401: 999-1006, 2016.

17. Campos Arbulú AL, Sadava EE, Kerman J, Fernández Vila JM, Mezzadri NA. Medicina (Buenos Aires) 76: 249-250, 2016.

18. Undre S, Munz Y, Moorthy K, Martin S, Rockall T, Vale J and Darzi A: Robot-assisted laparoscopic adrenalectomy: Preliminary UK results. BJU Int 93: 357-359, 2004.

19. Brunaud L, Ayav A, Zarnegar R, Rouers A, Klein M, Boissel P and Bresler L: Prospective evaluation of 100 robotic-assisted unilateral adrenalectomies. Surgery 144: 995-1001, 2008.

20. Agcaoglu O, Aliyev S, Karabulut K, Mitchell J, Siperstein A and Berber E: Robotic versus laparoscopic resection of large adrenal tumors. Ann Surg Oncol 19: 2288-2294, 2012.

21. Economopoulos KP, Mylonas KS, Stamou AA, Theocharidis V, Sergentanis TN, Psaltopoulou T and Richards ML: Laparoscopic versus robotic adrenalectomy: A comprehensive meta-analysis. Int J Surg 38: 95-104, 2017.

22. Burttet LM, Abreu FJDS, Varaschin GA, Silva B and Berger M: Robotic assisted laparoscopic excision of a retroperitoneal Ganglioneuroma. Int Braz J Urol 43: 997-997, 2017.

23. Deniwar A, Mohamed HE, Noureldine SI and Kandil E: Robotic-assisted laparoscopic adrenalectomy for an adrenal adenoma. Gland Surg 4: 447-448, 2015.

24. Akarsu C, Dural AC, Kankaya B, Çelik MF, Köneş O, Mert M, Kalayc1 MU and Alıs H: The early results of our initial experience with robotic adrenalectomy. Ulus Cerrahi Derg 30: 28-33, 2014.

25. Brandao LF, Autorino R, Laydner H, Haber GP, Ouzaid I, De Sio M, Perdonà S, Stein RJ, Porpiglia F and Kaouk JH: Robotic versus laparoscopic adrenalectomy: A systematic review and meta-analysis. Eur Urol 65: 1154-1161, 2014.

26. Yates J, Uberoi J and Munver R: Robot-assisted laparoscopic partial adrenalectomy: A case report and review of the literature. J Robot Surg 4: 149-154, 2010.

This work is licensed under a Creative Commons Attribution-NonCommercial-NoDerivatives 4.0 International (CC BY-NC-ND 4.0) License. 